European journal of American studies

\title{
The Death and Resurrection of Brian Griffin
}

Brett Mills

\section{(2) OpenEdition}

\section{Journals}

Electronic version

URL: https://journals.openedition.org/ejas/12452

DOI: 10.4000/ejas.12452

ISSN: 1991-9336

\section{Publisher}

European Association for American Studies

Electronic reference

Brett Mills, "The Death and Resurrection of Brian Griffin", European journal of American studies [Online], 13-1 | 2018, Online since 26 June 2018, connection on 08 July 2021. URL: http:// journals.openedition.org/ejas/12452 ; DOI: https://doi.org/10.4000/ejas.12452

This text was automatically generated on 8 July 2021

Creative Commons License 


\title{
The Death and Resurrection of Brian Griffin
}

\author{
Brett Mills
}

1 What kinds of stories does American television tell about the death of animals? How are such deaths represented, and in what kinds of television do they appear? How are audiences positioned in relation to those deaths, and therefore what responses are viewers encouraged to have? And what does the representation of animal death tell us about American culture more broadly, and its relationships with animals more specifically? This essay uses a single case study to unpack how these questions might be answered, as a starting-point for reflection on American culture's use of animal death within the framework of storytelling in popular media. My article maintains that the representation of animal death in television is significant because it tells us something about both humans' understanding of death and the use (symbolic and otherwise) of animals in contemporary American culture. After all, as Jonathan Burt argues, "It is difficult to avoid the presence of death ... at all levels of inquiry into animal representation" (157). Here, Burt suggests that human cultures employ representations of animal death as a way of engaging with their own mortality in order to avoid confronting this issue directly. In this way, the animal is reduced to a vehicle through which an inescapable aspect of human existence can be simultaneously acknowledged and denied. Taking this further, Lori Marino and Michael Mountain postulate that humans' "mortal anxiety and denial lead ... to an increasingly dysfunctional relationship with the rest of the natural world" (6), as humans' refusal to accept their own mortality discourages engagement with the fragility of the world. On the other hand, this denial allows humans to assert their superiority over other beings, founded on the assumption that only humans have a sense of their own impending deaths. For many human cultures animals thus become a useful resource for displacing anxieties about mortality, enabling humans to acknowledge that which awaits us all while simultaneously refusing to face this fact directly.

2 My essay explores this phenomenon through the analysis of an example from popular television. In doing so, my article is attuned to the specificities of television, and 
therefore the kinds of stories that the medium is able-and likely-to tell. In particular, "the episodic nature of television remains an organizing principle" (McNutt 3) for its storytelling. That is, television's ability to offer narratives across multiple episodes, or for programs to be made up of multiple episodes each with their own self-contained narratives, encourages forms of storytelling different from those media which typically are not episodic, such as film or literature. This aspect matters because central to television representations are the ways in which these depictions are narrativized. To be sure, representation could be understood here simply as the visual and aural symbols that constitute a character. However, I aim to explore how these characters function within stories, and thus the narrative purposes to which they are put. After all, narratives imbue characters with socio-cultural meaning, transforming them into carriers of meaning and ideology. Moreover, thinking about narrative facilitates the exploration of the socio-cultural norms that enable stories to make sense, as any narrative's comprehensibility is dependent upon audiences bringing to it their understanding of how stories work and the norms that exist within the cultures invited to read it. Accordingly, the examination of stories may unearth dominant ideologies which are so persistent and normalized that they do not need to be asserted. In the end, Brian's role in Family Guy (Fox, since 1999) is significant not because of what it tells us about this particular animal death in this particular program; instead its very meaningfulness points at the much broader and ingrained understanding and use of animal death in contemporary American culture.

In doing so, this paper aligns itself with human-animal studies, which "explores the spaces that animals occupy in human social and cultural worlds and the interactions humans have with them" (DeMello 4). One of these interactions is representation, in two ways. First, the making of an animal representation is a process by which that depiction comes into being; secondly, readers cognitively interact with these representations in order to make sense of them. After all, "[i]t is by our use of things, and what we say, think and feel about them-how we represent them-that we give them a meaning" (Hall 3; original italics). This approach asserts that animals do not have inevitable, "natural" meanings that representations simply draw on. Instead, representation is a process by which something, such as an animal, comes to be meaningful. Furthermore, "the stakes in representing animals can be very high" (Rothfels xi), as these depictions can help encourage particular kinds of human-animal interactions and considerations. If animals are depicted as vermin, or as a threat to human safety, it is easier to legitimize their destruction; if animals are depicted as pets, it is easier to justify spending considerable amounts of money on their happiness; if animals are depicted as tasty, then the meat industry becomes legitimate. The contradictory nature of humans' categorization, and subsequent use, of other living beings is encapsulated in the title of Hal Herzog's 2011 book Some We Love, Some We Hate, Some We Eat: Why It's So Hard to Think Straight About Animals. This contradictoriness must somehow be legitimized, and thus it is necessary to "recognize the kind of stories we tell ourselves" (Fudge, Animal 16) that carry out that legitimization. Human-animal studies works to make visible these processes, and in doing so destabilizes both the kinds of stories that humans tell and humans' right to tell those stories. In doing so, it problematizes the authority humans give themselves to tell stories about other beings at all.

4 Accordingly, "animal studies pushes the limits of exclusively human ways of being" (McHugh, Animal Stories 7). It does so by opening up alternative readings of texts, which 
insist on seeing animals as textual elements in themselves, rather than-as is often the case-metaphors for the human. In this way, the ways in which humans represent animals reveal humans' categorization and use of animals-both as representations and, by extension, in the world beyond. Human-centered readings all too easily fail to take into account, and think through, the animal-ness of animal representations. In response, animal studies aims to write animals back into the narratives that contain them. Thus we may ask, "How might species life be configured in texts?" (McHugh, Animal Stories 9). Such a question makes explicit the work that goes into such configurations, rejecting the idea that representations of animals are inevitable, simple, or natural. Instead, they are cultural products, configured in ways that are comprehensible within the culture that produces them. Therefore, the representation of animal death in American television is a particular configuration of animal depiction, and it is the narrative purpose to which that representation is put that reveals human-animal relationships, along with the power structures that underpin these. Of course, acknowledging these power structures inherently raises the question of whether there are alternative ways for such stories to be told, or whether it is legitimate to tell them in the first place. Human-animal studies constitutes a foundational challenge to the right humans claim to tell stories about animals, and the purposes to which those stories are put. In telling such stories humans insist upon their ability to make sense of the non-human world, rendering it comprehensible to human cultures. This in itself asserts human mastery over the non-human world, as the rightto-speak-on-behalf-of presents an act of silencing those who are spoken about. By insisting on seeing representations of animals as indicative of humans' instrumentalization of other beings, rather than merely as resources useful as metaphors for the human, the practice of animals as narrative resources becomes apparent. The story of animal death that is explored here, then, is telling in that it reveals how human cultures render animals as little more than resources whose representational deaths are useful for human-centered concerns.

\section{Brian Griffin}

5 Brian Griffin is the dog in the American animated sitcom Family Guy. He has been one of the core characters in the family-based program since the series launched in January 1999. Family Guy is a "staple" (Booker 82) of contemporary American animated television, sitting alongside series such as The Simpsons (Fox, 1989-) and King of the Hill (Fox, 1997-2009). It focuses on the Griffin family, constituted by father Peter, mother Lois, and the children Meg, Chris, and Stewie. While ostensibly employing a relatively realistic form of animation, the program is renowned for its "inserts" (Booker 89) in which statements made by characters lead to cutaways of brief comic scenes that typically function as self-contained comic moments unrelated to the main plot. Brian represents another aspect of Family Guy that signals the show's contradictory relationship with its predominantly realist mode. While, visually, he is clearly a dog, he usually walks on his back two legs, speaks English, and interacts with the rest of the characters as if he was human. Much of the comedy that draws on Brian's character mocks his supposedly simplistic liberal views, whereby his performance of concerned intellectualism is found to conflict with his animalistic desires or when being moral is simply too hard to maintain socially. This conforms to the program's comic voice of "brash satire" and amoral nihilism, in which "virtually no topic is considered out of 
bounds," resulting in "jokes about Hitler and the Holocaust, violent death, rape, child abuse, [and] drug use" (Booker 92-94). Since the series mixes these different modes, it has been understood variably as magical realism (Crawford), "postmodern American satire" (DeRochi 40), and a program whose politics are so "arbitrary" (Sienkiwicz and Marx 115) as to render it socially inert. Indeed, the series sits squarely in the tradition of the family-based American animated sitcom which "tend[s] to challenge authority, mainly by exposing official hypocrisy" but whose politics is blunted as "the aesthetic distance of the cartoon allows mainstream viewers to discount the grotesquerie if they so desire" (Tueth 145-146).

6 This complexity is evident in the representation of Brian as both a dog and a human. For the most part, Brian narratively functions as a human while visually appearing as a dog. Episodes show him driving a car, eating a meal at the table with the family, or reading a book, exemplifying that, in many cases, his narrative role could be fulfilled by a human character. However, Family Guy finds humor in moments where Brian's dogness bursts through his humanity, suggesting that his place within the human world is merely a veneer masking his true animalistic nature. Accordingly, characters throw sticks to distract him mid-discussion, and he confesses embarrassedly to having dug through rubbish to find scraps to eat. More significantly, though, some episodes build their narratives entirely around his dog-ness, offering up a politics attuned to concerns over animal welfare. For example, in "Dog Gone" (season 8, episode 8), Brian joins an animal rights league after coming to realize that his family care less about the deaths of animals than they do about the demise of humans. Similarly, in "Brian: Portrait of a Dog" (season 1, episode 7), he is offended when Peter expects him to perform in an animal show, and ends up leaving the family for a time. To be sure, Brian can be involved in narratives which explore animal-related matters, while his dog-ness can be practically irrelevant in other episodes. This malleability demonstrates how human cultures "recruit animals to symbolize, dramatize, and illuminate aspects of their own experience and fantasies," while the representational tools struggle with "how we might capture the agency of another being" (Daston and Mitman 2; 5). That Brian can be a dog and not-a-dog at the same time, and that either of these aspects can take priority at any particular point in service of the narrative, indicates his position as a representational resource valuable only inasmuch as the narrative requires at any particular point.

7 To be sure, Brian is an animated dog in a cartoon sitcom. His animated status is significant, as animation allows for particular kinds of representations that would be understood quite differently in other genres or modes. In particular, animals are omnipresent in animation, largely as stand-ins for humans. This application of supposedly human-only characteristics to non-human animals is referred to as "anthropomorphism," a process that evidences how human cultures "use the animal in the service of human communication and human action" (Miles and Ibrahim 1866). Anthropomorphism suggests animals must evidence their human-ness in order to have access to representation, revealing human cultures' insistence on understanding the world in anthropocentric ways. But anthropomorphism is troubling, partly because it is seen as "bad" practice and thus "to be avoided" (Horowitz and Bekoff 23). However, some scholars have argued that this approach has prevented the acknowledgment of similarities in human and animal behaviors, resulting in "anthropodenial" (de Waal 69; 
original italics), which helps maintain the human-animal divide necessary for human cultures to naturalize their dominance.

8 For example, depictions of human-animal hybrids have been seen as one of the ways in which science fiction engages with debates about biomedicine and other technological advancements, meaning the genre explores "problems of human/animal relation" (Ferreira 224). Science fiction examines this hybridity as a potential "problem" and thereby responds to broader societal concerns about what happens to the category of "the human" if it is crossed with beings categorized as other species. Given that the rights that humans assert for themselves-and deny to other beings-are dependent on the certainty of "the human" as a meaningful category, destabilizing its boundaries has significant consequences for hitherto anthropocentric certainties (Piotrowska). While, as noted above, there are nevertheless some narratives in Family Guy in which Brian's dog-ness is foregrounded, he does typically not challenge the human-animal boundary. Instead, the "ambiguity or ambivalence in the language of animation" entails that representations of characters such as Brian can be "beasts and humans, or neither" because animation "dilute[s] the implications of meaning" (Wells, Animated Bestiary 3). As such, "[c]ross-species coupling is an endemic and unnoticed currency of the animated cartoon" (Wells, Animated Bestiary 4), since animation "prioritizes its capacity to resist 'realism' as a mode of representation" (Wells, Understanding Animation 25; original italics). That said, animation is not entirely divorced from conventions of representation that inform all modes of audiovisual culture, and a cartoon animal's animal-ness is a relevant and inescapable component of what is offered up for meaning. Indeed, it may well be the case that animation so commonly features animals because the fluid "animality" human cultures impose upon non-humans is easily aligned with the "plasmatic agency of animation" (Wells, "Rhetorics of Representation" 101), meaning that animals are a productive resource for the ways in which cartoons tell their stories.

However, delineating whether Brian should be primarily read as an animal, an animalas-metaphor-for-the-human, or an animated animal (in contrast to a live-action one) is not what is at stake here. Instead, it is precisely this fluidity which points to the usefulness of animal representations within contemporary American cartoon culture. While such representations may have import in terms of how they contribute to the real-world treatment of dogs, it is also significant that the image of a dog is a resource a cartoon can draw on in order for the narratives it tells to make sense. And, of course, it does matter that Brian is a dog, for this is what enables him to function within Family Guy in the role of a pet, as dogs are normalized as pets within American culture. He is not a crocodile, an elephant, or a fruitfly-and that is significant. That his dog-ness becomes practically invisible is testament to the "chaotic omnipresence" (McHugh, Dog 9) of dogs. Indeed, dogs are "the most storied of all pet animals" (Fudge, Pets 10). As I demonstrate below, the fact that Brian is a dog is key to his narrativized death; if he were not a dog, it would not have happened. As such, while his status as an animated animal questions the impulse simply to correlate this animal representation with understandings of dogs outside of narrative forms such as Family Guy, his dog-ness must be kept in mind, as it is vital to the meanings of his death. 


\section{Death}

In the November 2013 episode of Family Guy called "Life of Brian" (season 12, episode 6), Brian is killed. He is about to play hockey in the streets with Stewie, the baby in the Griffin family, when a speeding car runs him over. He is rushed to the vet, where medical professionals describe his injuries as too severe and call in the rest of the family to say goodbye to him. Brian thanks them for the life they have given him, and then he dies. Later in the episode, his funeral takes place (Fig. 1). Even though Family Guy typically employs a comic tone in which "derogatory speech is not only ritualized but is funny and has no consequence" (Ricke 121-122), the vast majority of this episode is presented in a serious manner, and the audience is invited to find Brian's death as traumatic as the characters in the program do. For example, Brian's final words to the family are, "You've given me a wonderful life. I love you all," and the camera slowly moves in as his eyes close. This moment is followed by close-ups of the family members crying, and the plaintive incidental music discourages reading this moment comically (Fig. 2). The episode then cuts to a shot from behind the family, as they huddle together around Brian's body, a scene which concludes with a slow fade to black. As such, this narrative event represents not only a disruption within the regular characters that have functioned as the program's comic dynamic, but also a rupture in the gag-laden form of storytelling which Family Guy offers as one of its key pleasures. Accordingly, Brian's death and the family's mourning is emphasized as an anomaly, representing one of the few times in the program where a genuinely meaningful emotional reaction is invited in audiences.

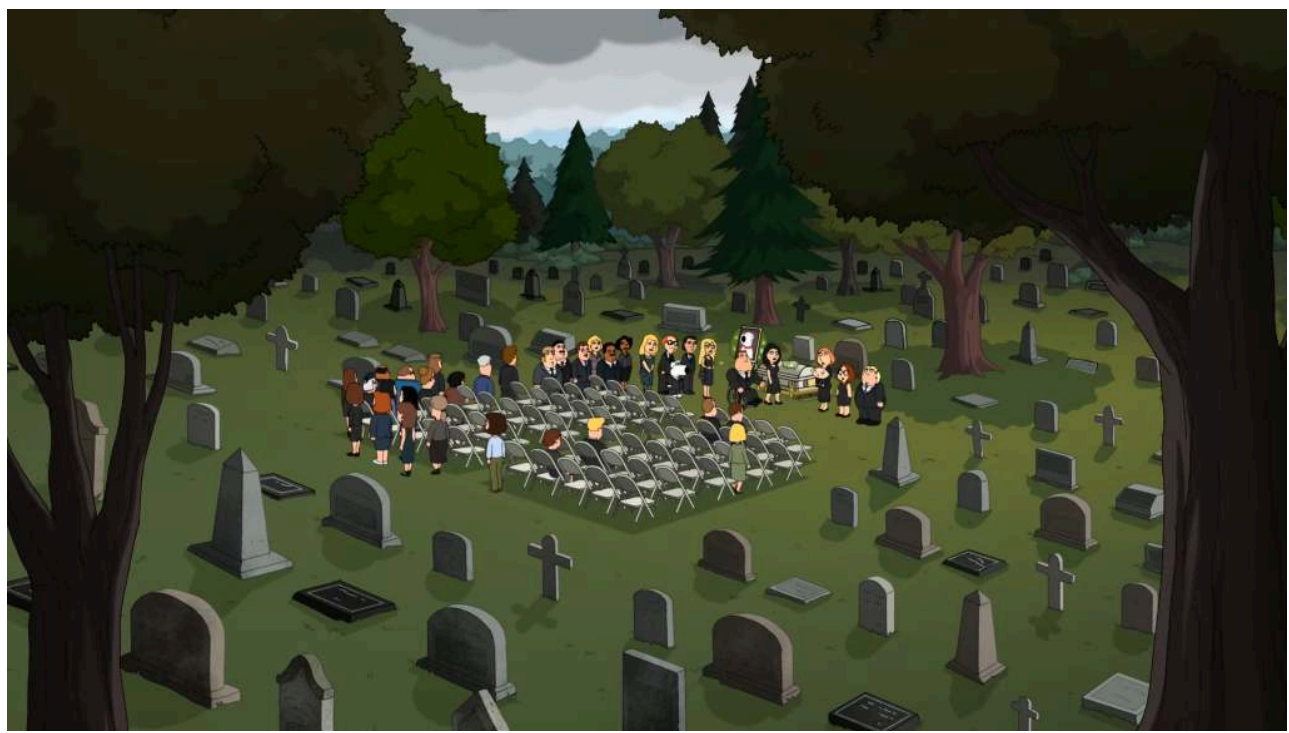

Fig. 1: Friends and family gather for Brian's funeral. Screenshot from the Family Guy episode "Life of Brian" (Netflix Austria). 


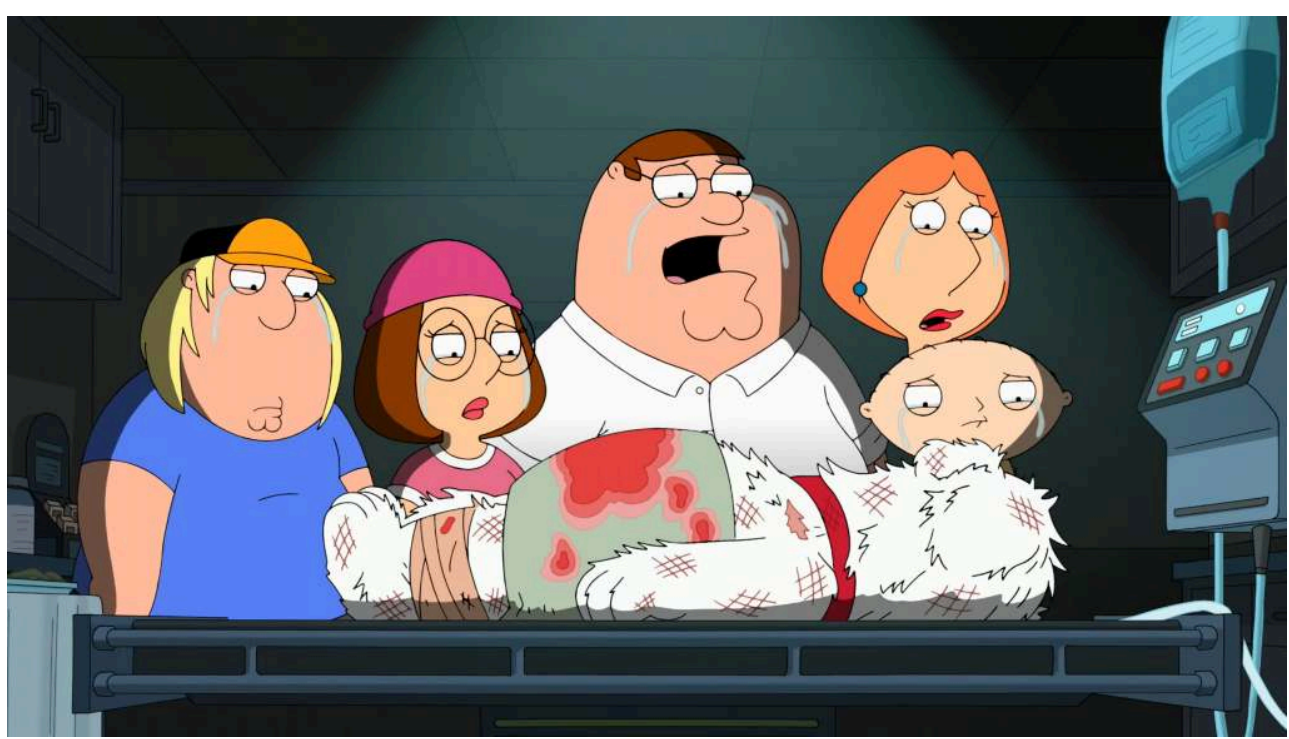

Fig. 2: Confronted with Brian's unexpected death, the family begins to cry. Screenshot from the Family Guy episode "Life of Brian" (Netflix Austria).

Indeed, the audience did have an emotional reaction. As one of the most popular characters in the program, the death of Brian attracted a lot of publicity, and many fans soon mobilized their unhappiness at the program's decision to kill off Brian. A petition on the website change.org garnered over 128,000 signatures calling for his return (Lombardi). The production team justified their decision to kill off Brian in many interviews. Steve Callaghan, Family Guy's executive producer, recounted that the idea came from a story conference, wherein a group of writers thought that dispensing with one of the series' recurring characters "could be a fun way to shake things up" (qtd. in Aguilera). When asked why Brian was chosen rather than one of the other main characters, he said, "As much as we love Brian, and as much as everyone loves their pets, we felt it would be more traumatic to lose one of the kids, rather than the family pet" (qtd. in Aguilera). The decision was thus species-based. And even though the death of Brian was depicted in a serious and somber manner departing from the program's usual tone, it was deemed to be manageable within the series in the way in which the death of a human character might not have been. Brian's death, as a character, thus arises entirely out of his status as a non-human character, narratively disposable to an extent that a human character might not be-despite his popularity. Indeed, for many of the program's fans, he is a more beloved character than other recurring ones, such as the Griffin children, Chris and Meg (see Compyjosh). This incongruity points toward industry assumptions about what is acceptable, or narratively manageable, within popular, mainstream animated programming such as Family Guy, where the human always trumps the non-human.

This narrative's legibility-and, in particular, its justification-arises from Western cultural understandings and expectations of the non-human beings we define as pets. The pet is, of course, an odd kind of animal, separate from what is typically characterized as "the natural world" and functioning entirely within the realm of the human. Indeed, the existence of many kinds of pets is precisely a result of the deliberate breeding of some animals in order to foreground desired behavioral characteristics and to reduce or remove others. That is, pets are not just animals enmeshed within everyday human activities; for many breeds, their very existence 
results from the human desire to create non-human beings that behave in ways we find acceptable. As such, Yi-Fu Tuan argues that pets are the result of human activities of dominance and affection, whereby humans express significant amounts of affection toward those non-human beings with which they share their living space (2). Indeed, this affection can assume dimensions that may open it to criticism, as humans pamper their pets with the help of a constantly growing pet industry producing goods that may not always be in the animals' best interests. But Tuan argues that such affection always functions within regimes of dominance, since pets must always fit within human daily activities and routines. Furthermore, they are expected to behave in ways acceptable to the family they share a living-space with, lest they be rehomed or, ultimately, euthanized. Indeed, humans are forever the ultimate arbiters of pets' ongoing existence, which shows that-despite the affection that clearly informs many petowner relationships-this is an unequal relationship within which the pet's behavior is always being assessed from a human vantage point.

Tuan notes how this uneven relationship plays out for the dog, where power can be exercised in a "willful," "arbitrary," and "perverse manner" (102). He sees this contradictory human behavior evidenced in the various uses to which domestic dogs are put, including working as guard dogs and hunting dogs. However, this paradox becomes even more evident in societal terms. After all, a nation such as America can pronounce itself to be dog-loving despite the fact that about two million dogs a year are euthanized in American dog shelters. The dog is thus loved, a part of the family, man's best friend, called upon to labor, and easily put to death. While Tuan focuses on actual dogs in the real world, I suggest that media representations of dogs draw on similar cultural contradictions which, in the end, always prioritize the human. Indeed, the Family Guy production team can pronounce Brian both loved and easier to kill off than the human characters, which shows that animal representations function within regimes of dominance and affection, as well. Furthermore, such representations help normalize societal understandings of pets such as dogs, which then render humans' dominance of other species not only legitimate but necessary. Accordingly, representations of fictional animals rely on the same discourses that shape behavior toward pets in the real world.

Indeed, this idea may be taken a step further. Erica Fudge argues that "humans represent animals only in order to represent human power over animals" (Animal 152). In this context, animal death is a recurring trope in audiovisual media. This nearomnipresence results from the fact that "the animal is especially suited to embody death's inevitability," since their non-human animality connotes "the movement of life that they intrinsically incarnate" (Bellour 288; 290). Pets are particularly useful in representational terms because "the modern urban pet is not a real animal" (Baker 13; original italics) and is instead a living thing defined by its purpose for humans.

One of the purposes to which human cultures put the representation of pets is that of enabling the discussion of death in a manner that does not require humans to acknowledge their own mortality. As a result, children's literature often explores death through the proxy of stories about pets. These animal narratives thus offer a space for children to attend to matters such as loss and grief in a manner that is both close and removed (see Corr). As for real-life pets, "[r]esearch indicates that many [owners] ... think about their animal companions' deaths while the animals are still well" (Hewson 431), because the shorter life spans of most pets compared to humans means that the 
inevitable loss of the pet is part and parcel of the pet-keeping activity. Accordingly, death is forever present in human-pet relationships. It is thus unsurprising that human cultures draw on audiovisual forms such as television in a manner which results in the "supplementation of animal-for-human death" (O'Brien 48). Dogs play a particular role in this context, as "[t]ime, aging, and necessary death ... are recurring subjects of dog discourse" (Mangum 41) in human narratives.

The notion of "shaking things up," which Family Guy's executive producer refers to, could have been implemented in a variety of ways: the introduction of a new character or a change in the program's visual style, for example. But instead of probing these ideas and despite his role as a main character in the show, Brian's status was deemed intangible enough that his removal would offer a useful narrative moment without upsetting the series as a whole. To be sure, "Life of Brian" engages with loss and grief in a manner comparable to children's literature, as the episode employs a pet as a vehicle for thinking about death. Significantly, it does so by killing off the key non-human character. Considering that Brian's human-like behavior tends to obscure his animality, it is significant that it is he who is chosen for death. Indeed, although Brian may drive a car and speak English and read books, his dog-ness is never entirely absent. As such, his acceptance into a human world of representation is forever limited given his animal status. In the end, his dog-ness renders him viable for execution, evidencing the ways in which animals are forever reduced to resources for anthropocentric narratives, especially when, like Brian, those animals spend most of their time functioning as proxy humans.

\section{Resurrection}

17 To be sure, there is a happy ending (of sorts) to this story. While the production team first insisted that Brian's death was permanent and not a publicity stunt, he came back to life only two episodes later, in the episode "Christmas Guy" (season 12, episode 8), via a time travel machine. The time travel narrative suggests that Brian, in fact, never died in the first place. Justifying the decision to run the three-episode storyline, the creator of Family Guy, Seth MacFarlane, said: "And thus endeth our warm, fuzzy holiday lesson: Never take those you love for granted, for they can be gone in a flash" (qtd. in Goldberg). However, he added that he could not imagine audiences would ever think that Brian's death would be permanent, saying the production team would need to be "fucking high" in order to do so. In hindsight, it would have been odd for a longrunning, successful series to rid itself of one of its key characters. However, the fact that many viewers did, indeed, believe that such a move was possible points to the disposability of animal characters, especially when their death is justified on the basis of preserving the human. While this happy ending could be seen as evidence for the affection with which animals-and animal representations-circulate, the whole storyline still demonstrates the narrative insecurity of animals compared to humans.

This primacy of the human becomes even more evident in view of the episodes between Brian's death and his eventual resurrection. Toward the end of "Life of Brian," the Griffins decide to get a new dog in order to fill the void Brian's death has left behind in the family. At a pet shop Peter chooses Vinny, a smooth-talking dog with an Italian accent, and takes him home. At first, Stewie, Brian's closest friend, is highly resistant to the idea of replacing Brian and plans to have Vinny removed. But once Vinny comforts 
Stewie as he mourns Brian, they become friends. By the end of the episode, Vinny has replaced Brian, and the role of the dog in the program has not been abandoned (Fig. 3). While Vinny's comic function, which focuses on the stereotypical aspects of his Italian character, renders him quite different from Brian in personality, in terms of narrative role, his primary function is to replace Brian. Indeed, the episode ends with Vinny sleeping at the foot of Stewie's bed, suggesting his closeness to Stewie in a manner comparable to his pairing with Brian. In this way, Vinny's dog-ness becomes more significant than his role as an Italian stereotype, and one dog is offered up to function narratively in an identical manner to the one that died only ten minutes earlier. I highlighted the importance of the serial, episodic nature of television to understanding how the medium functions above. In this context, this particular ending of "Life of Brian" signals that future episodes of Family Guy can employ the same basic narrative premise as the show used prior to Brian's death, thereby indicating the extent to which both Brian and Vinny's dog-ness are, effectively, one and the same. Their function as pets within the program's diegesis is thus in accord with their function as pets within the program's organizing structure.

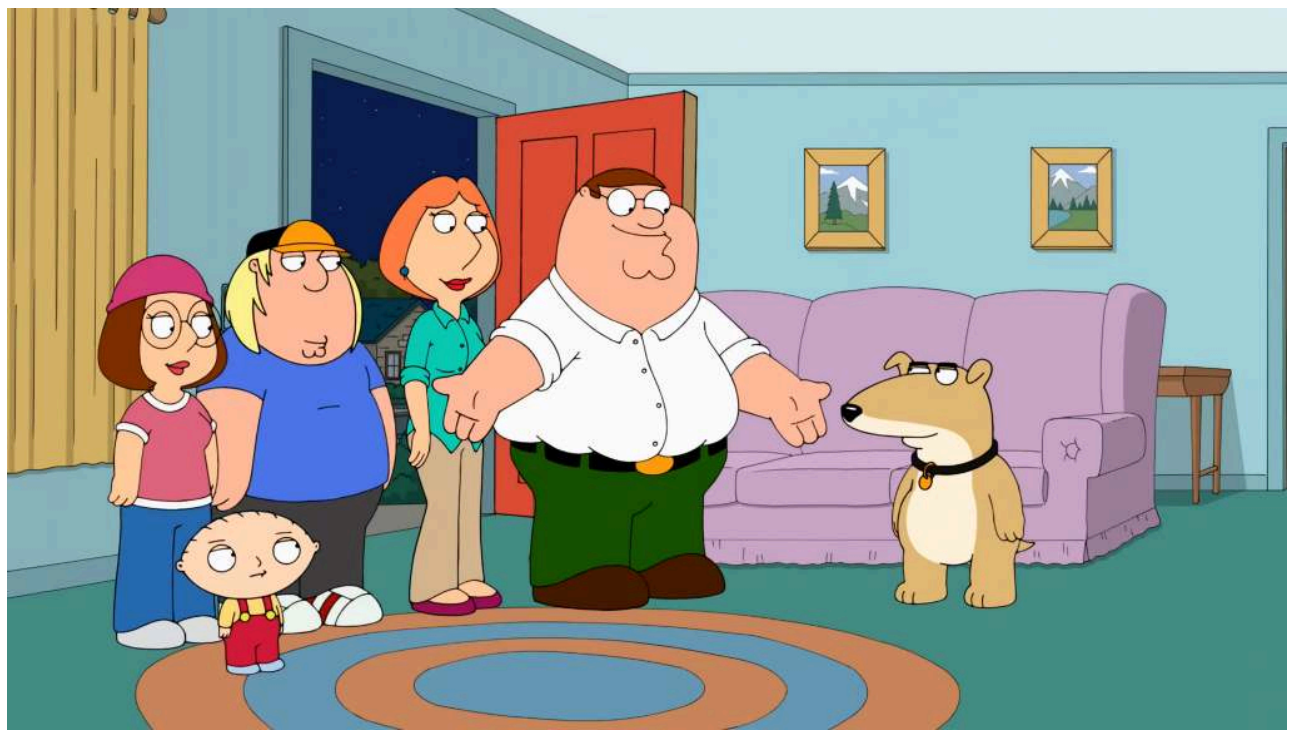

Fig. 3: Vinny replaces Brian between the latter's death and eventual resurrection. Screenshot from the Family Guy episode "Life of Brian" (Netflix Austria).

Interestingly, there is only room for one dog in such a format. This aspect becomes manifest when Brian returns from the dead. The narrative depicts Brian being saved, being pushed out of the way of the car that, in the original timeline, killed him. In this new alternative timeline, the Griffin family never encountered the other dog, Vinny, who consequently simply disappears from the program. The resurrection of Brian Griffin is dependent upon the death of Vinny-a death so certain that he never diegetically existed in the first place. While dogs may be permissible within Family Guy's narrative, it seems the show can incorporate only one at a time. The program's format allows for "a pet"; and while it may be Brian or Vinny, it cannot be both. Vinny is thus simply forgotten, irrelevant to the program's narrative because the role of pet is already filled. Brian and Vinny are interchangeable; pets first, and individuals a very distant second. Put simply, if we have Brian we do not need Vinny, and his death is so insignificant as not to warrant any kind of screen time at all. 
The death and resurrection of Brian Griffin, then, encapsulates how animal representations suggest the societal purposes to which animals are put. Both loved and disposable, their disposability evidences specieist hierarchies that consistently prioritize the human. The interchangeability of Brian and Vinny exposes the limited space for animals, as they function as "the pet," rather than individualized characters, in a manner not applicable to the human characters. Finally, the show's creators stressed that Brian's death was a storyline intended to remind viewers not to take those they love for granted; but this valuable moral lesson is enacted through the narrative sacrifice of an animal-not a human-character. As such, the annihilation of an animal representation-and the subsequent annihilation of the replacement animal's representation once the original has returned-is justified because it enables humans to learn a valuable lesson. As such, the death of two animals is acceptable as long as humans learn something. There might be no clearer evidence than this causal chain to showcase how human cultures employ animals as little more than resources, there for us to do what we want them to.

\section{BIBLIOGRAPHY}

Aguilera, Leanne. “Family Guy's Shocking Death: Boss Reveals Why They Decided to Kill Off [Spoiler]!” E! Online. 24 Nov. 2013. Web. 1 June 2017.

Baker, Steve. Picturing the Beast: Animals, Identity, and Representation. Urbana: U of Illinois P, 2001. Print

Bellour, Raymond. "Hitchcock: The Animal, Life and Death." Animal Life and the Moving Image. Ed. Michael Lawrence and Laura McMahon. London: British Film Institute, 2015. 288-297. Print.

Booker, M. Keith. Drawn to Television: Prime-Time Animation from The Flintstones to Family Guy. Westport, CT: Praeger, 2006. Print.

“Brian: Portrait of a Dog." Writ. Gary Janetti. Dir. Michael Dante DiMartino. Family Guy: Season 1. Twentieth Century Fox, 2004. DVD.

Burt, Jonathan. "Morbidity and Vitalism: Derrida, Bergson, Deleuze, and Animal Film Imagery." Configurations 14.1-2 (2006): 157-179. Print.

“Christmas Guy.” Writ. Patrick Meighan. Dir. Greg Colton. Family Guy: Season 12. Twentieth Century Fox, 2014. DVD.

Compyjosh. "Best Family Guy Characters." The Top Tens,. n.d. Web. 1 June 2017.

Corr, Charles A. "Pet Loss in Death-Related Literature for Children." Omega: Journal of Death and Dying 48.4 (2003): 399-414. Print.

Crawford, Alison. “'Oh Yeah!': Family Guy as Magical Realism.” Journal of Film and Video 61.2 (2009): 52-69. Print.

Daston, Lorraine, and Gregg Mitman. Thinking with Animals: New Perspectives on Anthropomorphism. New York: Columbia UP, 2005. 1-14. Print.

European journal of American studies, 13-1 | 2018 
DeMello, Margo. Animals and Society: An Introduction to Human-Animal Studies. New York: Columbia UP, 2012. Print.

DeRochi, Jack. “'What Have You Learned?': Considering a New Hermeneutic of Satire in Family Guy." Studies in American Humor 3.17 (2008): 35-48. Print.

de Wall, Frans. The Ape and the Sushi Master: Cultural Reflections by a Primatologist. London: Penguin, 2001. Print.

“Dog Gone.” Writ. Steve Callaghan. Dir. Julius Wu. Family Guy: Season 8. Twentieth Century Fox, 2009. DVD.

Ferreira, Aline. "Primate Tales: Interspecies Pregnancy and Chimerical Beings." Science Fiction Studies 35.2 (2008): 223-237. Print.

Fudge, Erica. Animal. London: Reaktion Books, 2002. Print.

---. Pets. Stocksfield: Acumen, 2008. Print.

Goldberg, Lesley. "Family Guy: Did Brian Return from the Dead?” The Hollywood Reporter. 15 Dec. 2013. Web. 1 June 2017.

Hall, Stuart. "Introduction." Representation: Cultural Representations and Signifying Practices. Ed. Stuart Hall. London: Sage, 1997. 1-11. Print.

Hewson, Caroline. “Grief for Pets Part 2: Realistic Client Care So That You 'Do No Harm.” Veterinary Ireland Journal 4.8 (2014): 431-436. Web. 1 June 2017.

Herzog, Hal. Some We Love, Some We Hate, Some We Eat: Why It's So Hard to Think Straight About Animals. New York: Harper Perennial, 2011. Print.

Horowitz, Alexandra C., and Mark Bekoff. "Naturalizing Anthropomorphism: Behavioral Prompts to Our Humanizing of Animals." Anthrozoös 20.1 (2007): 23-35. Print.

"Life of Brian." Writ. Alex Carter. Dir. Joseph Lee. Family Guy: Season 12. Twentieth Century Fox, 2014. DVD.

Lombardi, Ken. "Family Guy: Brian Griffin Comes Back from the Dead." CBS News. 16 Dec. 2013. Web. 1 June 2017.

McHugh, Susan. Animal Stories: Narrating Across Species Lines. Minneapolis: U of Minnesota P, 2011. Print.

---. Dog. London: Reaktion Books, 2004. Print.

McNutt, Myles. "Binge-Reviews?: The Shifting Temporalities of Contemporary TV Criticism." Film Criticism 40.1 (2016): 1-3. Print.

Mangum, Teresa. “Dog Years, Human Fears.” Representing Animals. Ed. Nigel Rothfels.

Bloomington: Indiana UP, 2002. 35-47. Print.

Marino, Lori, and Michael Mountain. "Denial of Death and the Relationship between Humans and Other Animals." Anthrozoös 28.1 (2016): 5-21. Print.

Miles, Chris, and Yasmin Ibrahim. "Deconstructing the Meerkat: Fabular Anthropomorphism, Popular Culture, and the Market." Journal of Marketing Management 29.15-16 (2013): 1862-1880. Print.

O’Brien, Sarah. “Why Look at Dead Animals?" Framework: The Journal of Cinema and Media 57.1 (2016): 32-57. Print. 
Piotrowska, Monika. “Transferring Morality to Human-Nonhuman Characters." The American Journal of Bioethics 14.2 (2014): 4-12. Print.

Ricke, LaChrystal D. “Funny or Harmful?: Derogatory Speech on Fox's Family Guy." Communication Studies 63.2 (2012): 119-135. Print.

Rothfels, Nigel. "Introduction.” Representing Animals. Ed. Nigel Rothfels. Bloomington: Indiana UP, 2002. vii-xv. Print.

Sienkiwicz, Matt, and Nick Marx. "Click Culture: The Perils and Possibilities of Family Guy and Convergence Era Television." Communication and Critical/Cultural Studies 11.2 (2014): 103-119. Print.

Tuan, Yi-Fu. Dominance and Affection: The Making of Pets. New Haven, CT: Yale UP, 1984. Print.

Tueth, Michael V. "Back to the Drawing Board: The Family in Animated Television Comedy." Prime Time Animation: Television Animation and American Culture. Ed. Carol A. Stabile and Mark Harrison. New York: Routledge, 2003. 133-146. Print.

Wells, Paul. The Animated Bestiary: Animals, Cartoons, and Culture. New Brunswick, NJ: Rutgers UP, 2009. Print.

---. Understanding Animation. London: Routledge, 1998. Print.

---. “'You Can See What Species I Belong To, But Don't Treat Me Lightly': Rhetorics of Representation in Animated Animal Narratives." Animal Life and the Moving Image. Ed. Michael Lawrence and Laura McMahon. London: British Film Institute, 2015. 95-107. Print.

\section{ABSTRACTS}

This essay explores the animated American sitcom Family Guy (Fox, 1999-) as a case study for thinking about the use of animals in narratives. It focuses on episodes in which the program's dog, Brian, is killed and subsequently resurrected. Brian is a useful subject for this examination in view of his hybrid dog/human status. My discussion of Brian's death and subsequent resurrection demonstrates how narratives exploit animals for anthropocentric purposes, enabling human cultures to engage with topics such as death. In doing so, my essay evidences how animals are little more than narrative resources, used by programs for decidedly human ends.

INDEX

Keywords: Family Guy, death, animal representation, television, anthropocentrism, animation, dogs

\section{AUTHOR}

\section{BRETT MILLS}

Brett Mills is a senior lecturer in Film and Television Studies at the University of East Anglia. He is the author of Animals on Television: The Cultural Making of the Non-Human (2017), The Sitcom (2009), and Television Sitcom (2005), and co-author of ReadingMedia Theory: Thinkers, Approaches, Contexts, which is currently in its second edition (2012). 